\title{
ENDOGENOUS SKILL FORMATION AND THE SOURCE COUNTRY EFFECTS OF INTERNATIONAL LABOR MARKET INTEGRATION
}

\author{
HARTMUT EGGER \\ GABRIEL FELBERMAYR
}

CESIFO WORKING PAPER No. 2018

CATEGORY 4: LABOUR MARKETS

JUNE 2007

\footnotetext{
An electronic version of the paper may be downloaded

- from the SSRN website:

wWw.SSRN.com

- from the RePEc website:

www.RePEc.org

- from the CESifo website:

www.CESifo-group.de
} 


\title{
ENDOGENOUS SKILL FORMATION AND THE SOURCE COUNTRY EFFECTS OF INTERNATIONAL LABOR MARKET INTEGRATION
}

\begin{abstract}
With endogenous skills and given technology, labor market integration necessarily lowers welfare of the left-behind in a poor sending country, even if all agents face identical emigration probabilities. This is in sharp contrast to the case of exogenous skill supply.
\end{abstract}

JEL Code: F22, J24.

Keywords: labor market integration, migration, endogenous skill formation.

\author{
Hartmut Egger \\ Socioeconomic Institute \\ University of Zurich \\ Zürichbergstr. 14 \\ 8032 Zurich \\ Switzerland \\ egger@wwi.unizh.ch
}

\author{
Gabriel Felbermayr \\ Economics Department \\ University of Tübingen \\ Nauklerstr. 47 \\ 72074 Tübingen \\ Germany \\ gabriel.felbermayr@uni-tuebingen.de
}

May 15, 2007

The authors thank Guido Tabellini as well as their colleagues Kim Eun Young, Sang Min Park, Janina Satzer and Thomas Welsch for constructive critique. 


\section{Introduction}

There is a well-established literature on the interplay between globalization and human capital formation. While previous studies have focused on the nexus between education and trade liberalization ${ }^{1}$, the role of skill formation in the process of labor market integration has received less attention. ${ }^{2}$ This is surprising for two reasons: first, there is persuasive empirical evidence on the increasing importance of international labor mobility (see Docquier and Marfouk, 2006) and, second, labor market integration clearly exhibits an effect on expected wage rates and thus on education incentives.

This note sheds light on the consequences of labor market integration for per capita income and welfare of the left-behind source country population. It also determines the distributional consequences within this group. To highlight the role of endogenous education choices, we model emigration as the outcome of a lottery with the same probability of emigration for all skill groups. ${ }^{3}$ In this case, and if skills are exogenous, GDP per capita and welfare of the left-behind do not depend on the emigration rate. However, if changes in the emigration probability lead to adjustments in the skill composition, both GDP per capita and welfare of the left-behind must fall. The reason is that labor market integration dissociates ex ante education incentives of potential emigrants and the ex post skill intensity which would be optimal for non-migrants. This is a fairly general result that does not hinge on specific assumptions on the production technology or on the distribution of innate ability in the population.

In the next section, we set up our theoretical framework. The results are derived in

\footnotetext{
${ }^{1}$ See Findlay and Kierzkowski (1983) for an early contribution, and Janeba (2003) for more recent work.

${ }^{2}$ Recent theoretical work on the brain drain is an exception (see Stark et al. 1998, and Beine et al., 2007, and the references therein).

${ }^{3}$ Docquier and Marfouk (2006) estimate rates of emigration into OECD countries by skill group. On average, educated workers are more mobile. However, the degree of heterogeneity is high: In the two largest source countries, Mexico and Turkey, emigration rates do not depend on skills. In addition emigration rates for low-skilled workers may be substantially underestimated, as the data ignores low-skilled illegal immigrants). In a supplement, which is attached to this working paper, we account for the case of brain drain where only high-skilled workers may emigrate. It turns out that our main results do not depend on the assumption of identical emigration probabilities across skill groups.
} 
Section 3. Section 4 briefly discusses the robustness of our findings.

\section{Model setup}

We consider a small one-sector economy, 'South'. The representative firm employs highskilled $(H)$ and low-skilled labor $(L)$ to manufacture a homogeneous good $Y$, according to a linear-homogeneous production function, which we write in intensive form as $Y=L f(h)$, where $h \equiv H / L . \quad f(\cdot)$ has the usual properties $f^{\prime}(\cdot)>0$ and $f^{\prime \prime}(\cdot)<0$ and satisfies the Inada conditions. All markets are perfectly competitive and workers are paid their marginal products.

The population size in the small economy is normalised to one. The local supply of high-skilled and low-skilled labor is endogenous and depends on two things: the education decision of individuals and the emigration rate of high-skilled and low-skilled workers. Individuals differ with respect to their innate learning ability $a \in[0,1]$ which is distributed according to some c.d.f. $G(a)$, with $G^{\prime}(a)>0$. Educated agents supply $a$ efficiency units of high-skilled labor $H$, while uneducated ones supply one unit of low-skilled labor $L$. Hence, $1-a$ describes the private cost of education in terms of lower working time. Risk neutral agents maximize expected income by choosing whether or not to get educated. The expected income depends on learning abilities, wages and the propensity to emigrate for the two skill types. Throughout our analysis, we focus on the empirically relevant case and assume that Southern total factor productivity (TFP) is so low that both skill types benefit from emigration to the large, rich 'North', whose wages are exogenous from the Southern perspective. Following Stark et al. (1998), Beine et al. (2001, 2007), emigration is modeled as a lottery outcome. All individuals face the same probability of successful emigration, $p \in(0,1)$.

Using subscripts to denote skill classes and an asterisk for Northern magnitudes, expected wages per efficiency unit are given by $w_{H}^{e}=p w_{H}^{*}+(1-p) w_{H}$ and $w_{L}^{e}=$ $p w_{L}^{*}+(1-p) w_{L}$. The marginal individual $\bar{a}$, that is indifferent between education and non-education, is determined by the condition $\bar{a}=1 / \omega^{e}$, where $\omega^{e} \equiv w_{H}^{e} / w_{L}^{e}$ is the expected skill premium. One can rewrite that condition in terms of within-country wage 
inequality measures $\omega \equiv w_{H} / w_{L}$ and $\omega^{*} \equiv w_{H}^{*} / w_{L}^{*}$, and between-country income inequality $q \equiv w_{L}^{*} / w_{L}:$

$$
\bar{a}=\frac{1}{\omega^{e}}=\frac{1-p+p q}{(1-p) \omega+p \omega^{*} q} .
$$

The supply of low-skilled and high-skilled (non-emigrated) labor is given by $L^{s}=(1-$ p) $G(\bar{a})$, and $H^{s}=(1-p) \int_{\bar{a}}^{1} a d G(a)$, respectively. Labor market clearing implies that the skill intensity of Southern production is given by

$$
h(\bar{a}) \equiv \frac{\int_{\bar{a}}^{1} a d G(a)}{G(\bar{a})}
$$

where $\lim _{\bar{a} \rightarrow 0^{+}} h(\bar{a})=\infty, \lim _{\bar{a} \rightarrow 1^{-}} h(\bar{a})=0$, and $d h(\bar{a}) / d \bar{a}<0$. Clearly, without a skillbias in the emigration probability, any shock that improves the incentives for education results in higher $h$.

The competitive wage premium in South and between country income inequality are given by

$$
\omega=\frac{f^{\prime}(h(\bar{a}))}{f(h(\bar{a}))-h(\bar{a}) f^{\prime}(h(\bar{a}))} \text { and } q=\frac{w_{L}^{*}}{f(h(\bar{a}))-h(\bar{a}) f^{\prime}(h(\bar{a}))}
$$

where the first expression implies a positive relationship between $\omega$ and $\bar{a}$. The equilibrium cut-off ability, skill intensity, and wage inequality are jointly determined by equations (1)(3). Figure 1 illustrates the equilibrium in $1 / \omega^{e}, \bar{a}$-space. The upward-sloping 45 -degree line depicts the left-hand-side of (1). Substituting (2) into (3) and using the resulting expression in (1), the right-hand-side of (1) gives a function $\Omega(\bar{a})>0$ with $\Omega^{\prime}(\bar{a})<0$ and $\lim _{\bar{a} \rightarrow 0} \Omega(\bar{a})=\infty$. Hence, there exists a unique equilibrium, with the equilibrium cutoff ability level being denoted by $\bar{a}_{p}$ to indicate the dependence of the cutoff level on the prevailing emigration rate, $p$.

From Figure 1, we can also read off the comparative-static effects of a change in $p$ on $\bar{a}_{p}$. Noting $\partial \Omega(\cdot) / \partial p>,=,<0$ if $\omega>,=,<\omega^{*}$ and $\Omega^{\prime}(\cdot)<0$ (from above), it follows from the implicit function theorem that an increase in $p$ shifts, for a given $\omega^{e}$, the $\Omega$ locus in figure 1 to the right (to the left) if $\omega>\omega^{*}\left(\omega<\omega^{*}\right)$, leading to a higher (lower) cutoff ability level $\bar{a}_{p} \cdot{ }^{4}$ Hence, the incentive effect of the emigration lottery depends on a

\footnotetext{
${ }^{4}$ In the borderline case of $\omega=\omega^{*}$, the position of the $\Omega$-locus remains unaffected and $\bar{a}_{p}$ becomes independent of $p$.
} 


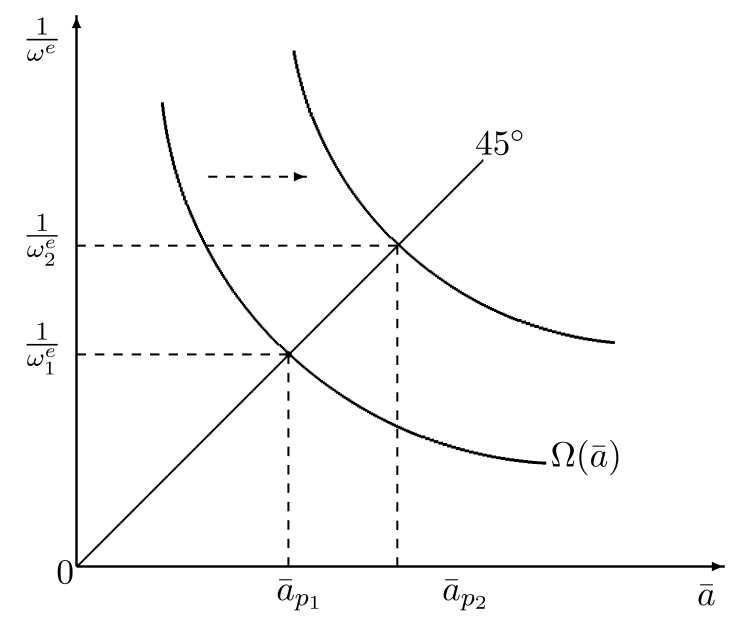

Figure 1: Determination of equilibrium and comparative statics if $\omega>\omega^{*}$.

comparison of within-country wage inequality measures. Recent empirical evidence shows that the Theil coefficient of wage inequality is 0.07 in the 119 poorest countries while it is 0.03 in the richest 25 (Galbraith and Lu, 2001). ${ }^{5}$ This indicates that wage inequality is substantially larger in poor source countries of emigration relative to rich (mainly OECD) destination countries. Hence, in the empirically relevant case, we can expect a higher probability of successful emigration to have a positive impact on $\bar{a}_{p}$ and thus a negative impact on the incentives for education. ${ }^{6}$ However, our main welfare results do not require any assumption on the relation between $\omega$ and $\omega^{*}$.

\section{Welfare and distribution effects of an emigration lottery}

For the welfare analysis, we look at Southern non-migrants and use changes of their total income as the relevant welfare criterion. Total income of this group is given by (1 p) $y\left(\bar{a}_{p}\right)=(1-p) G\left(\bar{a}_{p}\right) f\left(h\left(\bar{a}_{p}\right)\right)$, where $y\left(\bar{a}_{p}\right)$ denotes GDP per capita and $(1-p) G\left(\bar{a}_{p}\right)=$

\footnotetext{
${ }^{5}$ Similar comparisons hold for overall inequality, see Deininger and Squire (1996).

${ }^{6}$ This outcome differs substantially from the findings in the brain drain literature, where the additional education incentives from an increase in the emigration probability has been put forward as a source for a brain gain in the presence of a brain drain (see Stark et al., 1998; Beine et al., 2001).
} 
$(1-p) L^{S}$ is domestic low-skilled labor supply in equilibrium. The impact of a change in the emigration probability from $\left(p_{1}\right.$ to $\left.p_{2}\right)$ on income of the left-behind population can then be written as $V\left(p_{1}, p_{2}\right)=\left(1-p_{2}\right)\left[y\left(\bar{a}_{p_{2}}\right)-y\left(\bar{a}_{p_{1}}\right)\right] .{ }^{7}$ This implies that we can focus on the effect of a change in $p$ on GDP per capita, $y\left(\bar{a}_{p}\right)$, in order to determine the respective welfare effects for non-migrants. Then, the following result is immediate.

Proposition 1. An increase in the emigration probability $p$ leaves GDP per capita and total income of non-migrants unaffected if cutoff ability level $\bar{a}_{p}$ and thus the relative skill supply $h\left(\bar{a}_{p}\right)$ are constant. If the increase in pleads to an adjustment of $\bar{a}_{p}$ and thus $h\left(\bar{a}_{p}\right)$, then both GDP per capita and total income of non-migrants must decline $\left(V\left(p_{1}, p_{2}\right)<0\right)$.

Proof. We can write $d y\left(\bar{a}_{p}\right) / d p=\left[d y\left(\bar{a}_{p}\right) / d \bar{a}_{p}\right] \times\left[d \bar{a}_{p} / d p\right]$, where $d y\left(\bar{a}_{p}\right) / d \bar{a}_{p}=G^{\prime}\left(\bar{a}_{p}\right) f\left(h\left(\bar{a}_{p}\right)\right)+$ $G\left(\bar{a}_{p}\right) f^{\prime}\left(h\left(\bar{a}_{p}\right)\right) h^{\prime}\left(\bar{a}_{p}\right)$. Substituting $h^{\prime}\left(\bar{a}_{p}\right) \times\left[G\left(\bar{a}_{p}\right) / h\left(\bar{a}_{p}\right)\right]=-G^{\prime}(\bar{a})\left[1+\bar{a}_{p} / h\left(\bar{a}_{p}\right)\right]$, according to (2), implies

$$
\frac{d y\left(\bar{a}_{p}\right)}{d \bar{a}_{p}}=G^{\prime}\left(\bar{a}_{p}\right)\left[f(\cdot)-f^{\prime}(\cdot) h\left(\bar{a}_{p}\right)\left(1+\frac{\bar{a}_{p}}{h\left(\bar{a}_{p}\right)}\right)\right],
$$

Using (3) and (1), we obtain

$$
\frac{d y\left(\bar{a}_{p}\right)}{d \bar{a}_{p}}=G^{\prime}\left(\bar{a}_{p}\right) f^{\prime}(\cdot)\left[\frac{p q}{\omega\left[(1-p) \omega+p \omega^{*} q\right]}\right]\left(\omega^{*}-\omega\right) .
$$

Noting from Section 2 that $d \bar{a}_{p} / d p>,=,<0$ if $\omega>,=,<\omega^{*}$, we can conclude that $d y\left(\bar{a}_{p}\right) / d p<0$ if $\omega \neq \omega^{*}$ and $d y\left(\bar{a}_{p}\right) / d p=0$ if $\omega=\omega^{*}$. Substituting this result in $V$ completes the proof of Proposition 1.

Labor market integration implies that the incentives for education in the South become increasingly dependent on Northern relative factor prices. However, only local technological conditions are relevant for maximizing GDP per capita (and thus overall income of Southern non-migrants). An increase in $p$ widens the gap between incentives and the optimal relative Southern skill intensity, as long as the factor price differential in the North and the

\footnotetext{
${ }^{7}$ The income of the ex post non-migrants prior to the change in $p$ is given by $\left(1-p_{1}\right) y\left(\bar{a}_{p_{1}}\right)-\left(p_{2}-\right.$ $\left.p_{1}\right) y\left(\bar{a}_{p_{1}}\right)$, where $\left(p_{2}-p_{1}\right) y\left(\bar{a}_{p_{1}}\right)$ denotes the income of ex post migrants prior to the change in $p$. Rearranging terms, the income of the ex post non-migrants prior to the change in $p$ can then be written as $\left(1-p_{2}\right) y\left(\bar{a}_{p_{1}}\right)$, while the respective income of this group is given by $\left(1-p_{2}\right) y\left(\bar{a}_{p_{2}}\right)$ after the change in $p$.
} 
South do not coincide (i.e., $\omega^{*} \neq \omega$ ). If the incentives for education do not change, i.e. if $\bar{a}$ is constant, the relative skill supply remains remains unaffected and so do GDP per capita and total income of the left-behind population. Hence, the negative welfare consequences of labor market integration do not arise in a model with exogenous skill supply, where the skill intensity of production remains unaffected if the emigration probability increases in a skill-neutral way.

Beyond the welfare consequences of emigration within non-migrants, we can also determine the distributional effects in the Southern economy. While the analysis in Section 2 suggests a trivial link between $\omega$ and $p$, education decisions also affect the number of efficiency units provided by the average high-skilled worker, so that distribution is also affected by a compositional factor. Denote the ratio of average high-skilled and low-skilled factor income by

$$
R\left(\bar{a}_{p}\right) \equiv \omega \rho\left(\bar{a}_{p}\right), \text { where } \rho\left(\bar{a}_{p}\right)=\frac{\int_{\bar{a}_{p}}^{1} a d G(a)}{1-G\left(\bar{a}_{p}\right)},
$$

corrects $\omega$ for the time costs of education. Then, the following Proposition can be derived.

Proposition 2. An increase in migration probability $p$ raises (reduces) the factor income ratio $R\left(\bar{a}_{p}\right)$, if wage inequality in the South is higher (lower) than wage inequality in the North, i.e. if $\omega>(<) \omega^{*}$.

Proof. We can use $h^{\prime}\left(\bar{a}_{p}\right)<0$, according to (2), and $d \omega / d h<0$, according to (3). This implies $d \omega / d \bar{a}_{p}>0$. Furthermore, we have $d \rho\left(\bar{a}_{p}\right) / d \bar{a}_{p}=\left[G^{\prime}\left(\bar{a}_{p}\right) \int_{\bar{a}_{p}}^{1}\left(a-\bar{a}_{p}\right) d G(a)\right] /[1-$ $\left.G\left(\bar{a}_{p}\right)\right]^{2}>0$. Putting together, we obtain $d R\left(\bar{a}_{p}\right) / d \bar{a}_{p}>0$. Noting finally $d \bar{a}_{p} / d p>,=,<0$ if $\omega>,=,<\omega^{*}$ from the analysis in Section 2, completes the proof of Proposition 2.

According to Proposition 2, the distributional consequences of emigration depend on whether wage inequality in the South is more or less pronounced than wage inequality in the North. Emigration into an egalitarian economy raises both wage inequality $\omega$ and average high-skilled relative to average low-skilled factor income $R\left(\bar{a}_{p}\right)$ in the South. The opposite holds true for emigration into a non-egalitarian country (with $\omega^{*}>\omega$ ). As empirical stylized facts indicate that wage inequality in the South is higher than wage 
inequality in the North, we can conclude that (skill-neutral) emigration not only lowers overall income of the left-behind but it also raises inequality by increasing $R\left(\bar{a}_{p}\right)$.

\section{Robustness and concluding remarks}

Before concluding, we consider two simple extensions to check the robustness of our results.

First, in virtually all countries some part of education is provided by the public sector. Denote by $D$ the fixed amount of public education spending, which is financed by a proportional tax $\tau \in(0,1)$ on local wage income. With respect to the education technology, we abstract from rivalry and let an educated worker with ability $a$ supply $a D$ efficiency units of high-skilled labor. The government budget constraint is

$$
D=\tau(1-p) G\left(\bar{a}_{p}\right) f\left(h\left(\bar{a}_{p}\right)\right) .
$$

Proposition 1 states that, if $\omega \neq \omega^{*}$, emigration lowers GDP per capita, $y\left(\bar{a}_{p}\right)=G\left(\bar{a}_{p}\right) f\left(h\left(\bar{a}_{p}\right)\right)$. Hence, with $D$ constant, equation (5) implies that the tax burden for non-migrants increases. All other things equal, this reinforces the negative effects of a migration lottery on the group of non-migrants. ${ }^{8}$

Second, there may be a positive externality of a better educated workforce. To account for this channel of influence let total factor productivity (TFP; $A$ ) depend on overall skill intensity in Southern production $h\left(\bar{a}_{p}\right)$, so that $y=A\left(h\left(\bar{a}_{p}\right)\right) G\left(\bar{a}_{p}\right) f\left(h\left(\bar{a}_{p}\right)\right)$. Then, with $\omega^{*}>\omega$, an increase in $p$ would stimulate education and result in a higher skill intensity of Southern production. This leads to a higher TFP level and therefore counteracts the negative income effects described in Proposition 1. Depending on the strength of this externality it cannot be generally excluded that a higher emigration rate makes the leftbehind population better off. However, in the empirically relevant case with $\omega^{*}<\omega$, the welfare loss materializes a fortiori.

To conclude, this note argues that labor market integration is likely to hurt nonmigrants in poor countries and, to the extent that rich destination countries are relatively

\footnotetext{
${ }^{8}$ In the presence of migration, the Southern policy makers may want to cut back on $D$. This incentive is taken into account in Egger et al. (2007).
} 
egalitarian, it tends to raise inequality in source countries.

\section{References}

[1] Beine, M., Docquier, F., Rapoport, H., 2001. Brain drain and economic growth: theory and evidence, Journal of Development Economics 64(1), 275-289.

[2] Beine, M., Docquier, F., Rapoport, H., 2007. Brain drain and human capital formation in developing countries: winners and losers, Economic Journal, forthcoming.

[3] Deininger, K., and Squire, L., 1996. A new data set measuring income inequality. World Bank Economic Review 10(3): 565-591.

[4] Docquier, F., and Marfouk, A., 2006. International migration by education attainment, 1990-2000. In: C. Ozden and M. Schiff (eds.), International migration, brain drain and remittances, New York: McMillan and Palgrave, Chapter 5: 151-199.

[5] Egger, H., Falkinger, J., and Grossmann, V., 2007, Brain drain, fiscal competition, and public education expenditure. IZA Discussion Paper no. 2747.

[6] Findlay, R., Kierzkowski, H., 1983. International trade and human capital: a simple general equilibrium model. Journal of Political Economy 91(6): 957-978.

[7] Galbraith, J. K., Lu, J., 2001. Measuring the evolution of inequality in the global economy. In: Galbraith, J.K., and Berner, M., eds., Inequality and industrial change: a global view. Cambridge University Press, p. 161-185.

[8] Janeba, E. (2003), Does trade increase inequality when skills are endogenous?, Review of International Economics 10(3), 885-898.

[9] Stark, O., Helmenstein, C., Prskawetz, A., 1998. Human capital depletion, human capital formation, an migration: a blessing or a curse?, Economics Letters 60(3), 363-367. 


\section{Supplement}

\section{Quality-selective migration lottery}

In sections 2 and 3 , we have studied the implications of a non-discriminatory migration lottery. In this section, we will briefly discuss the consequences of "quality-selective" migration policies, by assuming $p_{H}>p_{L}=0$. For the purpose of tractability, we consider a Cobb-Douglas production technology: $Y=G(\bar{a}) h_{E}^{\alpha}$, with $h_{E} \equiv\left(1-p_{H}\right) h(\bar{a})$ and $\alpha \in(0,1)$. Then the following Proposition can be formulated.

Proposition 3. Under a Cobb-Douglas production technology, introduction of a qualityselective migration policy (with $p_{H}>p_{L}=0$ ) reduces cutoff ability $\bar{a}$, GDP per capita $y$ and total income of non-migrants in the Southern economy.

Proof. A formal proof of Proposition 3 is presented below.

If the North introduces a quality-selective migration policy, high-skilled workers face an emigration probability $p_{H}>0$, while all low-skilled workers remain immobile. All other things equal, this raises the expected skill premium per efficiency unit $\omega^{e}$ (as $w_{H}^{*}>w_{H}$ has been assumed) and therefore provides additional incentives for acquiring education. As a consequence, cutoff ability $\bar{a}$ declines. Similar to the baseline scenario with identical emigration probabilities across skill groups, a positive emigration probability, $p_{H}>0$, drives a wedge between the ex ante education incentives of potential emigrants and the ex post skill-intensity which would be optimal for non-migrants. This reduces GDP per capita and total income of non-migrants.

While it is unambiguous that the overall impact of a quality selective migration lottery on non-migrants is negative, its distributional consequences are less clear. This has the following reason. In the case of a Cobb-Douglas production technology, the skill premium is given by $\omega=[\alpha /(1-\alpha)]\left[\left(1-p_{H}\right) h(\bar{a})\right]^{-1}$. Noting $h^{\prime}(\bar{a})<0$, according to (2), there are two counteracting effects of a marginal $p_{H}$ increase on skill premium $\omega$. On the one hand, for a given $\bar{a}$, the outflow of high-skilled workers reduces the skill intensity of Southern production and therefore raises the skill premium. On the other hand, a decline in the 
cutoff ability level implies that more people acquire education, so that high-skilled labor becomes a less scarce resource. For a given $p_{H}$ this leads to a lower skill premium. It is in general not clear, which of the two effects dominates. However, it is intuitive that the second effect is stronger if the elasticity of labor supply with respect to cutoff ability $\bar{a}$ is sufficiently high. As the impact of a $p_{H}$ increase on the skill premium per efficiency unit turns out to be ambiguous, it is not surprising that its impact on relative factor return $\Omega$ is ambiguous, as well. The compositional effect, however, reinforces the indirect negative effect on $\omega$, so that a decline in the skill premium is sufficient for a decline in relative factor return $\Omega$.

\section{Proof of Proposition 3}

Consider $p_{H}>p_{L}=0$ and $f\left(h_{E}\right)=h_{E}^{\alpha}$. Then, the equilibrium cutoff ability level is implicitly determined by

$$
\Gamma\left(\bar{a}, p_{H}\right) \equiv \frac{(1-\alpha) h_{E}^{\alpha}}{p_{H} w_{H}^{*}+\left(1-p_{H}\right) \alpha h_{E}^{\alpha-1}}-\bar{a},
$$

with $h_{E}=\left(1-p_{H}\right) h(\bar{a})$. Applying the implict function theorem, we obtain

$$
\frac{d \bar{a}}{d p_{H}}=-\frac{\partial \Gamma / \partial h_{E} \times\left(1-p_{H}\right) d h(\bar{a}) / d \bar{a}-1}{\partial \Gamma / \partial p_{H}-\partial \Gamma / \partial h_{E} \times h(\bar{a})} .
$$

Noting $\partial \Gamma / \partial h_{E}>0, \partial \Gamma / \partial p_{H}<0$ (due to $\left.w_{H}^{*}>w_{H}\right)$ and $h^{\prime}(\bar{a})<0$ (from (2)), proves $d \bar{a} / d p_{H}<0$.

Let us next consider the impact of $p_{H}$ on GDP per capita. For his purpose, we consider

$$
y=\frac{G(\bar{a})\left[\left(1-p_{H}\right) h(\bar{a})\right]^{\alpha}}{1-p_{H}(1-G(\bar{a}))} \equiv \tilde{y}\left(\bar{a}, p_{H}\right) .
$$

Differentiating $\tilde{y}(\cdot)$ with respect to $\bar{a}$ gives

$$
\frac{\partial \tilde{y}(\cdot)}{\partial \bar{a}}=\frac{G^{\prime}(\bar{a}) y \xi\left(\bar{a}, p_{H}\right)}{G(\bar{a})\left[1-p_{H}(1-G(\bar{a}))\right]}
$$

with $g(a)=d G(a) / d a$ and

$$
\xi\left(\bar{a}, p_{H}\right) \equiv\left(1-p_{H}\right)-\alpha\left[1-p_{H}(1-G(\bar{a}))\right] \frac{h(\bar{a})+\bar{a}}{h(\bar{a})} .
$$


Noting $\lim _{\bar{a} \rightarrow 0^{+}} \xi(\cdot)=(1-\alpha)\left(1-p_{H}\right), \lim _{\bar{a} \rightarrow 1^{-}} \xi(\cdot)=-\infty$ and $\partial \xi / \partial \bar{a}<0$, it is obvious that, for any $p_{H} \in[0,1)$, there exists a unique $\bar{a}^{*}\left(p_{H}\right) \in(0,1)$ that maximizes $\tilde{y}(\cdot)$.

Differentiating $\tilde{y}(\cdot)$ with respect to $p_{H}$, we further obtain

$$
\frac{\partial \tilde{y}(\cdot)}{\partial p_{H}}=\frac{(1-G(\bar{a})) y \psi\left(\bar{a}, p_{H}\right)}{\left(1-p_{H}\right)\left[1-p_{H}(1-G(\bar{a}))\right]}
$$

with

$$
\psi\left(\bar{a}, p_{H}\right) \equiv\left(1-p_{H}\right)-\alpha\left[1-p_{H}(1-G(\bar{a}))\right] \frac{1}{1-G(\bar{a})} .
$$

Comparing (S5) and (S7), we see that

$$
\xi(\cdot)>,=,<\psi(\cdot) \quad \Longleftrightarrow \quad G(\bar{a}) h(\bar{a})>,=,<(1-G(\bar{a})) \bar{a} .
$$

Noting $G(\bar{a}) h(\bar{a})-(1-G(\bar{a})) \bar{a}=\int_{\bar{a}}^{1}(a-\bar{a}) d G(\bar{a})>0$, according to (2), we can therefore conclude that $\xi(\cdot)>\psi(\cdot)$. This, however, implies that $\partial \tilde{y} /\left.\partial p_{H}\right|_{\bar{a}=\bar{a}^{*}}<0$. Consider a lottery with $p_{H}^{0} \in(0,1)$ (and $p_{L}=0$ ) and denote by $\bar{a}_{0}$ the respective cutoff ability level under decentralized education decisions. Then, it follows from eqs. (S4) and (S5) that there exists a $\bar{a}^{*}\left(p_{H}^{0}\right) \in(0,1)$ which leads to $\tilde{y}\left(\bar{a}^{*}, p_{H}^{0}\right) \geq \tilde{y}\left(\bar{a}_{0}, p_{H}^{0}\right)$ - where a strict inequality holds if $\bar{a}^{*} \neq \bar{a}_{0}$. Furthermore, it follows from eqs. (S6)-(S8) that there exists a $p_{H}^{1}<p_{H}^{0}$, such that $\tilde{y}\left(\bar{a}^{*}, p_{H}^{1}\right)>\tilde{y}\left(\bar{a}^{*}, p_{H}^{0}\right)$. Noting that $\bar{a}^{*}=\bar{a}_{0}$ if $p_{H}^{0}=0$, this proves that introduction of a quality-selective migration lottery with $p_{H}>p_{L}=0$ reduces GDP per capita in the Southern economy. ${ }^{9}$

In a final step, we have to show that a quality-selective migration lottery with $p_{H}>$ $p_{L}=0$ lowers total income of Southern non-migrants. We use indices 1 and 0 to refer to a situation with and without migration, respectively. Then, $w_{H}^{0} H_{0}^{S}+w_{L}^{0} L_{0}^{S}$ denotes total Southern factor income in the absence of migration. Furthermore, $p_{H} w_{H}^{0} H_{0}^{S}+p_{H} w_{L}^{0}\left(L_{0}^{S}-\right.$ $L_{1}^{S}$ ) denotes wage payments to workers who emigrate after introduction of a qualityselective migration lottery. Finally, total wage income of non-migrants after introduction

\footnotetext{
${ }^{9}$ Evaluating $(\mathrm{S} 1)$ at $p_{H}=0$ gives $\bar{a}=[(1-\alpha) / \alpha] h(\bar{a})$. Furthermore, substituting (S5) into (S4) end evaluating the resulting expression at $p_{H}=0$ gives $\partial \tilde{y}(\cdot) / \partial \bar{a}=G^{\prime}(\bar{a}) f(h(\bar{a}))[(1-\alpha)-\alpha \bar{a} / h(\bar{a})]$. This proves that the decentralized education decisions maximize GDP per capita if $p_{H}=0$, implying $\bar{a}^{*}=\bar{a}_{0}$ in this case.
} 
of a migration lottery is given by $\left(1-p_{H}\right) w_{H}^{1} H_{1}^{S}+w_{L}^{1} L_{1}^{S}$. Hence, the introduction of a migration lottery has a negative (positive) impact on total income of non-migants if

$$
w_{H}^{0} H_{0}^{S}+w_{L}^{0} L_{0}^{S}-p_{H} w_{H}^{0} H_{0}^{S}-p_{H} w_{L}^{0}\left(L_{0}^{S}-L_{1}^{S}\right)>(<)\left(1-p_{H}\right) w_{H}^{1} H_{1}^{S}+w_{L}^{1} L_{1}^{S} .
$$

Rearranging terms, we can rewrite inequality (S9) in the following way:

$$
\begin{aligned}
& \underbrace{\left(1-p_{H}\right) H_{1}^{S}\left(w_{H}^{0}-w_{H}^{1}\right)+\left(w_{L}^{0}-w_{L}^{1}\right) L_{1}^{S}}_{\equiv T_{1}} \\
& \quad+\underbrace{\left(1-p_{H}\right)\left[w_{H}^{0}\left(H_{0}^{S}-H_{1}^{S}\right)+w_{L}^{0}\left(L_{0}^{S}-L_{1}^{S}\right)\right]}_{\equiv T_{2}}>(<) 0
\end{aligned}
$$

Let us consider the sign of $T_{1}$ first. From (S10), it follows that

$$
T_{1}>,=,<0 \Longleftrightarrow \frac{\left(1-p_{H}\right) H_{1}^{S} w_{H}^{1}}{L_{1}^{S} w_{L}^{1}}\left(\frac{w_{H}^{0}}{w_{H}^{1}}-1\right)>,=,<1-\frac{w_{L}^{0}}{w_{L}^{1}}
$$

Noting $f^{\prime}\left(h_{E}\right)=\alpha h_{E}^{\alpha-1}=w_{H}, f\left(h_{E}\right)-f^{\prime}\left(h_{E}\right) h_{E}=(1-\alpha) h_{E}^{\alpha}=w_{L}$ and $h_{E}=(1-$ $\left.p_{H}\right) H^{S} / L^{S}$, we obtain $\left(1-p_{H}\right) H_{1}^{S} w_{H}^{1} /\left(L_{1}^{S} w_{L}^{1}\right)=\alpha /(1-\alpha)$. This implies $T_{1}>,=,<0$ $\Leftrightarrow \alpha w_{H}^{0} / w_{H}^{1}+(1-\alpha) w_{L}^{0} / w_{L}^{1}>,=,<1$. Noting further that $w_{H}^{0} / w_{H}^{1}=\left(h_{E}^{0} / h_{E}^{1}\right)^{\alpha-1}$, $w_{L}^{0} / w_{L}^{1}=\left(h_{E}^{0} / h_{E}^{1}\right)^{\alpha}$ and using $\eta \equiv h_{E}^{0} / h_{E}^{1}$, we can therefore conclude:

$$
T_{1}>,=,<0 \quad \Longleftrightarrow \quad \eta^{\alpha}\left[\alpha \eta^{-1}+(1-\alpha)\right]>,=,<1 .
$$

Differentiating $\zeta(\eta) \equiv \eta^{\alpha}\left[\alpha \eta^{-1}+(1-\alpha)\right]$, we see that $\zeta^{\prime}(\eta)<0$ if $\eta \in(0,1)$, while $\zeta^{\prime}(\eta)>0$ if $\eta>1$. Put differently, $\zeta(\eta)$ has a minimum at $\eta=1$. According to (S11), this implies $T_{1} \geq 0$ (with a strict inequality if $\eta \neq 1$ ).

To determine the sign of $T_{2}$, we use $H_{1}^{S}-H_{0}^{S}=\int_{\bar{a}_{1}}^{\bar{a}_{0}} a d G(a)$ and $L_{0}^{S}-L_{1}^{S}=\int_{\bar{a}_{1}}^{\bar{a}_{0}} 1 d G(a)$. Noting further $w_{L}^{0}=\bar{a}_{0} w_{H}^{0}$ from (1), we obtain $T_{2}=(1-p) w_{H}^{0} \int_{\bar{a}_{1}}^{\bar{a}_{0}}\left(\bar{a}_{0}-a\right) d G(a)$, which is strictly positive as $\bar{a}_{0}>\bar{a}_{1}$ if $p_{H}>p_{L}=0$ and $w_{H}^{*}>\max \left(w_{H}^{0}, w_{H}^{1}\right)$ (see above). As a consequence, we have $T_{1}+T_{2}>0$, so that non-migrants are worse off after introduction of a quality-selective migration lottery. This completes the proof of Proposition 3. QED. 


\section{CESifo Working Paper Series}

(for full list see www.cesifo-group.de)

1952 Michela Redoano, Fiscal Interactions Among European Countries. Does the EU Matter?, March 2007

1953 Stefan C. Wolter, Rémy Hübschi and Matthias Müller, Push or Pull? An Empirical Analysis of the Demand for Individual Project Grants from the Swiss National Science Foundation, March 2007

1954 Scott Alan Carson, African-American and White Inequality in the American South: Evidence from the $19^{\text {th }}$ Century Missouri State Prison, March 2007

1955 Peter Egger, Marko Koethenbuerger and Michael Smart, Do Fiscal Transfers Alleviate Business Tax Competition? Evidence from Germany, March 2007

1956 Panu Poutvaara and Lars-H. R. Siemers, Smoking and Social Interaction, March 2007

1957 Stephan Danninger and Fred Joutz, What Explains Germany's Rebounding Export Market Share?, March 2007

1958 Stefan Krasa and Mattias Polborn, Majority-efficiency and Competition-efficiency in a Binary Policy Model, March 2007

1959 Thiess Buettner and Georg Wamser, Intercompany Loans and Profit Shifting Evidence from Company-Level Data, March 2007

1960 Per Pettersson-Lidbom and Mikael Priks, Behavior under Social Pressure: Empty Italian Stadiums and Referee Bias, April 2007

1961 Balázs Égert and Carol S. Leonard, Dutch Disease Scare in Kazakhstan: Is it real?, April 2007

1962 Paul De Grauwe and Pablo Rovira Kaltwasser, Modeling Optimism and Pessimism in the Foreign Exchange Market, April 2007

1963 Volker Grossmann and Thomas M. Steger, Anti-Competitive Conduct, In-House R\&D, and Growth, April 2007

1964 Steven Brakman and Charles van Marrewijk, It's a Big World After All, April 2007

1965 Mauro Ghinamo, Paolo M. Panteghini and Federico Revelli, FDI Determination and Corporate Tax Competition in a Volatile World, April 2007

1966 Inés Macho-Stadler and David Pérez-Castrillo, Optimal Monitoring to Implement Clean Technologies when Pollution is Random, April 2007 
1967 Thomas Eichner and Ruediger Pethig, Efficient $\mathrm{CO}_{2}$ Emissions Control with National Emissions Taxes and International Emissions Trading, April 2007

1968 Michela Redoano, Does Centralization Affect the Number and Size of Lobbies?, April 2007

1969 Christian Gollier, Intergenerational Risk-Sharing and Risk-Taking of a Pension Fund, April 2007

1970 Swapan K. Bhattacharya and Biswa N. Bhattacharyay, Gains and Losses of India-China Trade Cooperation - a Gravity Model Impact Analysis, April 2007

1971 Gerhard Illing, Financial Stability and Monetary Policy - A Framework, April 2007

1972 Rainald Borck and Matthias Wrede, Commuting Subsidies with two Transport Modes, April 2007

1973 Frederick van der Ploeg, Prudent Budgetary Policy: Political Economy of Precautionary Taxation, April 2007

1974 Ben J. Heijdra and Ward E. Romp, Retirement, Pensions, and Ageing, April 2007

1975 Scott Alan Carson, Health during Industrialization: Evidence from the $19^{\text {th }}$ Century Pennsylvania State Prison System, April 2007

1976 Andreas Haufler and Ian Wooton, Competition for Firms in an Oligopolistic Industry: Do Firms or Countries Have to Pay?, April 2007

1977 Eckhard Janeba, Exports, Unemployment and the Welfare State, April 2007

1978 Gernot Doppelhofer and Melvyn Weeks, Jointness of Growth Determinants, April 2007

1979 Edith Sand and Assaf Razin, The Role of Immigration in Sustaining the Social Security System: A Political Economy Approach, April 2007

1980 Marco Pagano and Giovanni Immordino, Optimal Regulation of Auditing, May 2007

1981 Ludger Woessmann, Fundamental Determinants of School Efficiency and Equity: German States as a Microcosm for OECD Countries, May 2007

1982 Bas Jacobs, Real Options and Human Capital Investment, May 2007

1983 Steinar Holden and Fredrik Wulfsberg, Are Real Wages Rigid Downwards?, May 2007

1984 Cheng Hsiao, M. Hashem Pesaran and Andreas Pick, Diagnostic Tests of Cross Section Independence for Nonlinear Panel Data Models, May 2007

1985 Luis Otávio Façanha and Marcelo Resende, Hierarchical Structure in Brazilian Industrial Firms: An Econometric Study, May 2007 
1986 Ondřej Schneider, The EU Budget Dispute - A Blessing in Disguise?, May2007

1987 Sascha O. Becker and Ludger Woessmann, Was Weber Wrong? A Human Capital Theory of Protestant Economic History, May 2007

1988 Erkki Koskela and Rune Stenbacka, Equilibrium Unemployment with Outsourcing and Wage Solidarity under Labour Market Imperfections, May 2007

1989 Guglielmo Maria Caporale, Juncal Cunado and Luis A. Gil-Alana, Deterministic versus Stochastic Seasonal Fractional Integration and Structural Breaks, May 2007

1990 Cláudia Costa Storti and Paul De Grauwe, Globalization and the Price Decline of Illicit Drugs, May 2007

1991 Thomas Eichner and Ruediger Pethig, Pricing the Ecosystem and Taxing Ecosystem Services: A General Equilibrium Approach, May 2007

1992 Wladimir Raymond, Pierre Mohnen, Franz Palm and Sybrand Schim van der Loeff, The Behavior of the Maximum Likelihood Estimator of Dynamic Panel Data Sample Selection Models, May 2007

1993 Fahad Khalil, Jacques Lawarrée and Sungho Yun, Bribery vs. Extortion: Allowing the Lesser of two Evils, May 2007

1994 Thorvaldur Gylfason, The International Economics of Natural Resources and Growth, May 2007

1995 Catherine Roux and Thomas von Ungern-Sternberg, Leniency Programs in a Multimarket Setting: Amnesty Plus and Penalty Plus, May 2007

1996 J. Atsu Amegashie, Bazoumana Ouattara and Eric Strobl, Moral Hazard and the Composition of Transfers: Theory with an Application to Foreign Aid, May 2007

1997 Wolfgang Buchholz and Wolfgang Peters, Equal Sacrifice and Fair Burden Sharing in a Public Goods Economy, May 2007

1998 Robert S. Chirinko and Debdulal Mallick, The Fisher/Cobb-Douglas Paradox, Factor Shares, and Cointegration, May 2007

1999 Petra M. Geraats, Political Pressures and Monetary Mystique, May 2007

2000 Hartmut Egger and Udo Kreickemeier, Firm Heterogeneity and the Labour Market Effects of Trade Liberalisation, May 2007

2001 Andreas Freytag and Friedrich Schneider, Monetary Commitment, Institutional Constraints and Inflation: Empirical Evidence for OECD Countries since the 1970s, May 2007

2002 Niclas Berggren, Henrik Jordahl and Panu Poutvaara, The Looks of a Winner: Beauty, Gender, and Electoral Success, May 2007 
2003 Tomer Blumkin, Yoram Margalioth and Efraim Sadka, Incorporating Affirmative Action into the Welfare State, May 2007

2004 Harrie A. A. Verbon, Migrating Football Players, Transfer Fees and Migration Controls, May 2007

2005 Helmuth Cremer, Jean-Marie Lozachmeur and Pierre Pestieau, Income Taxation of Couples and the Tax Unit Choice, May 2007

2006 Michele Moretto and Paolo M. Panteghini, Preemption, Start-Up Decisions and the Firms' Capital Structure, May 2007

2007 Andreas Schäfer and Thomas M. Steger, Macroeconomic Consequences of Distributional Conflicts, May 2007

2008 Mikael Priks, Judiciaries in Corrupt Societies, June 2007

2009 Steinar Holden and Fredrik Wulfsberg, Downward Nominal Wage Rigidity in the OECD, June 2007

2010 Emmanuel Dhyne, Catherine Fuss, Hashem Pesaran and Patrick Sevestre, Lumpy Price Adjustments: A Microeconometric Analysis, June 2007

2011 Paul Belleflamme and Eric Toulemonde, Negative Intra-Group Externalities in TwoSided Markets, June 2007

2012 Carlos Alós-Ferrer, Georg Kirchsteiger and Markus Walzl, On the Evolution of Market Institutions: The Platform Design Paradox, June 2007

2013 Axel Dreher and Martin Gassebner, Greasing the Wheels of Entrepreneurship? The Impact of Regulations and Corruption on Firm Entry, June 2007

2014 Dominique Demougin and Claude Fluet, Rules of Proof, Courts, and Incentives, June 2007

2015 Stefan Lachenmaier and Horst Rottmann, Effects of Innovation on Employment: A Dynamic Panel Analysis, June 2007

2016 Torsten Persson and Guido Tabellini, The Growth Effect of Democracy: Is it Heterogenous and how can it be Estimated?, June 2007

2017 Lorenz Blume, Jens Müller, Stefan Voigt and Carsten Wolf, The Economic Effects of Constitutions: Replicating - and Extending - Persson and Tabellini, June 2007

2018 Hartmut Egger and Gabriel Felbermayr, Endogenous Skill Formation and the Source Country Effects of International Labor Market Integration, June 2007 